\title{
MORFOGÊNESE QUATERNÁRIA E INTEMPERISMO: COLÚVIOS DO PLANALTO DO ITATIAIA
}

\author{
May Christine MODENESI \\ Maria Cristina Motta de TOLEDO
}

\begin{abstract}
RESUMO
No setor inferior das vertentes do planalto do Itatiaia $(2.300-2.500 \mathrm{~m})$ ocorrem duas gerações de colúvios que testemunham fases de intensificação das ações erosivas nas vertentes. Estudo mineralógico e micromorfológico permitiu reconhecer tendência geral laterítica nos materiais de alteração in situ e colúvios. A análise micromorfológica dos colúvios evidencia mistura de materiais com diferentes graus de alteração, mais especialmente em CII, caracterizado por contrastes maiores que o comum num mesmo nível de perfis de alteração. Intensamente argilificados mas pouco pedogeneizados, ricos em fragmentos das rochas subjacentes e com menores contrastes de alteração, os colúvios CI poderiam ter sido originados por movimentos de massa que atingiram o regolito em maior profundidade. Em CII, altero e litorrelíquias bem menos comuns e grãos de esqueleto sempre menores indicariam materiais de origem inicialmente mais evoluídos; mistura de graus extremos de alteração sugere retrabalhamento por processos superficiais de coluviação, com inclusão de fragmentos de rocha menos alterada durante o transporte vertente abaixo. A atuação de diferentes processos nas vertentes permite inferir variações nas condições ambientais do planalto. De climas úmidos mais estáveis, e talvez mais quentes, favoráveis à alteração do regolito, ter-se-ia passado a uma fase de intensificação ou concentração das chuvas, capaz de explicar o desencadeamento das corridas de lama que depositaram CI. Nos últimos 8.000 anos, condições úmidas mas com maiores oscilações da temperatura, incluindo fases de maior intensidade dos processos de gelifração, teriam sido responsáveis pela deposição dos materiais, ora finos ora cascalhentos, das seqüências CII. Estas variações não foram entretanto suficientes para mudar a tendência laterítica da alteração, que teria persistido após o último máximo glacial.
\end{abstract}

\begin{abstract}
On the lower slopes of the Itatiaia Plateau $(2,300-2,500 \mathrm{~m})$ are found two generations of colluvia, which indicate phases of intensification of slope erosion. A general lateritic trend characterizes the regolith and colluvia. Micromorphological analysis of the colluvia shows a mixture of materials at different stages of weathering, especially in $\mathrm{C}_{\mathrm{II}}$, which presents stronger contrasts than is usual at any given level of weathering profiles. $\mathrm{C}_{\mathrm{I}}$ colluvia, which are clayey, rich in fragments of underlying rocks show little pedogenic development and less weathering contrasts, might have originated in mass movements reaching deep into the regolith. In $\mathrm{C}_{\mathrm{II}}$, rock and weathering relicts are less common and skeleton grains smaller, indicating provenance from materials originally more evolved. The mixture of materials at extreme degrees of weathering suggests reworking by surficial colluviation processes with the inclusion of poorly weathered rock fragments by downslope transportation. The presence of different processes acting on the slopes allows inference on past environments on the plateau. There would have been a transition from wet, more stable climates, perhaps warmer (favorable to the weathering of the regolith), to a phase of intensification or concentration of rainfall, which would explain the mudflows which deposited $\mathrm{C}_{\mathrm{I}}$. In the last 8,000 years, conditions still humid but with stronger oscillations of temperature, as well as phases of more intense gelifraction, would explain the deposition of the weathered materials of the $\mathrm{C}_{\mathrm{II}}$ sequences. Such variations, however, were not sufficient to divert the lateritic trend of the weathering, that would have persisted after the last glacial maximum.
\end{abstract}

\section{INTRODUÇÃO}

O planalto do Itatiaia encontra-se no topo do maciço do mesmo nome, a $2.300-2.500 \mathrm{~m}$ de altitude, aproximadamente $500 \mathrm{~m}$ acima das cimeiras das serras da Mantiqueira (planaltos de
Campos do Jordão e Monte Verde) e da Bocaina. Nestes dois núcleos de serras altas brasileiras, DE MARTONNE (1940) reconheceu vestígios da mais antiga superfície de aplainamento do Brasil de sudeste, a "alta superfície dos campos". Existem controvérsias sobre a idade geo- 
morfológica desta superfície aplainada em relação a uma superfície ligeiramente mais baixa e de mais ampla distribuição espacial, a chamada superfície das "cristas médias", originalmente proposta por DE MARTONNE. Para FREITAS (1951) e ALMEIDA (1964 e 1976), a superfície dos altos campos resultaria de soerguimentos tectônicos que teriam alçado setores da superfície das cristas médias a níveis topograficamente mais elevados. KING (1956) partilha da idéia de que os testemunhos destas altas superfícies pertencem a uma só e mesma fase de aplainamento.

$\mathrm{O}$ maciço do Itatiaia constitui uma intrusão alcalina de arranjo semicircular - "ring dyke" - (TEIXEIRA, 1961) que foi soerguida, juntamente com o embasamento granítico e gnáissico da Mantiqueira, durante os processos que criaram as montanhas de blocos falhados na fachada atlântica do Brasil de sudeste. A área de pesquisa inclui-se nos setores expostos dos altos maciços alcalinos que emergem dos níveis dos altos platôs da Mantiqueira. Substrato alcalino e modificações climáticas conseqüentes do ressalto marcaram a evolução quaternária do Itatiaia, acentuando a originalidade da paisagem de montanha tropical (MODENESI, 1992).

As rochas presentes na intrusão alcalina (figura 1) são sienitos, foiaítos, pulaskitos, quartzosienitos, granitos alcalinos, brechas e tinguaítos, compondo tipos petrográficos diferenciados entre si principalmente pela variação da proporção relativa dos minerais constituintes. De modo geral, das bordas para o centro do maciço, as rochas passam de insaturadas, ricas em feldspatóides, a saturadas e finalmente supersaturadas (granito alcalino) (LAMEGO, 1936; RIBEIRO FILHO, 1967 e PENALVA, 1967). Os sienitos do Itatiaia foram datados em $66 \mathrm{~m}$. a. (AMARAL et al., 1967).

A influência orográfica no clima do Itatiaia evidencia-se na temperatura média anual de $11,5^{\circ} \mathrm{C}, 3^{\circ} \mathrm{C}$ inferior à registrada no planalto de Campos do Jordão, e nos totais anuais de pluviosidade, entre 1.967 e $3.037 \mathrm{~mm}$, superiores aos observados na cimeira vizinha $(1.205$ a $2.289 \mathrm{~mm}$ ).

Campos de altitude com ecossistemas rupestres (AB'SABER, 1989), incluindo bolsões arbustivos, situam-se acima do limite das florestas orográficas que recobrem a face da Serra da Mantiqueira voltada para o Atlântico.

No setor inferior das vertentes do vale do ribeirão das Flores, depósitos de tálus e rampas de colúvio (figura 2) documentam fases intensas de erosão e deposição ocorridas durante o Quaternário. A caracterização morfológica e sedimentológica dos materiais coluviais permitiu reconhecer a atuação de diferentes processos, provavelmente relacionados à variação das con- dições ambientais (MODENESI, 1989 e 1992). Este estudo mineralógico e micromorfológico teve por objetivo confirmar as interpretações anteriores sobre a gênese dos materiais coluviais e conhecer melhor as relações entre morfogênese, sedimentação, alteração e pedogênese no planalto do Itatiaia. Os dados obtidos deverão contribuir para a reconstituição da evolução quaternária das cimeiras do Brasil de sudeste.

\section{METODOLOGIA}

Estudos de alteração das formações superficiais têm grande interesse geomorfológico, uma vez que tipo e grau de intemperismo refletem as condições ambientais e a intensidade da evolução dos materiais superficiais e do relevo.

Os colúvios das baixas vertentes do vale do ribeirão das Flores foram analisados segundo diretrizes metodológicas descritas em trabalhos anteriores sobre o planalto de Campos do Jordão (MODENESI, 1980, 1983 e 1988). A partir da compartimentação geomorfológica, procurou-se evidenciar as variações de alteração das formações superficiais e suas relações com a dinâmica morfogenética.

No levantamento das formações superficiais, foram considerados os materiais distribuídos (1) longitudinalmente aos vales, em áreas de vertentes convexas (lombas), côncavas (anfiteatros) ou paralelas aos eixos de drenagem, e (2) transversalmente, nesse caso correspondendo às toposseqüências clássicas. Os perfis mais representativos, escolhidos por apresentar as seqüências mais completas e com melhores evidências de transporte, foram descritos e amostrados em trincheiras que expõem os materiais de vertente em toda a sua profundidade, incluindo rocha alterada in situ e colúvios relacionados a três fases de movimentação de detritos nas encostas.

Para a análise granulométrica, mineralógica e micromorfológica destes materiais foram coletadas noventa amostras, em camadas ou horizontes diferenciados por suas características morfológicas, que refletem tanto os processos sedimentares como os intempéricos e pedogenéticos. Os perfis amostrados situam-se geralmente sobre quartzo-sienito e apenas um deles ocorre sobre brechas (figura 1).

Os limites das classes granulométricas são os da escala de Wentworth: argila: $<0,004 \mathrm{~mm}$; silte: entre 0,004 e $0,062 \mathrm{~mm}$; areias: entre 0,062 e $2 \mathrm{~mm}$; grânulos: entre 2 e $4 \mathrm{~mm}$; seixos: entre 4 e $64 \mathrm{~mm}$; blocos: entre 64 e $256 \mathrm{~mm}$ e matacões: $>256 \mathrm{~mm}$.

Análise mineralógica por difração de raios-X foi realizada em 59 amostras de rocha alterada e colúvios. Foram analisadas amostras totais e frações argila e silte; tratamentos complemen- 

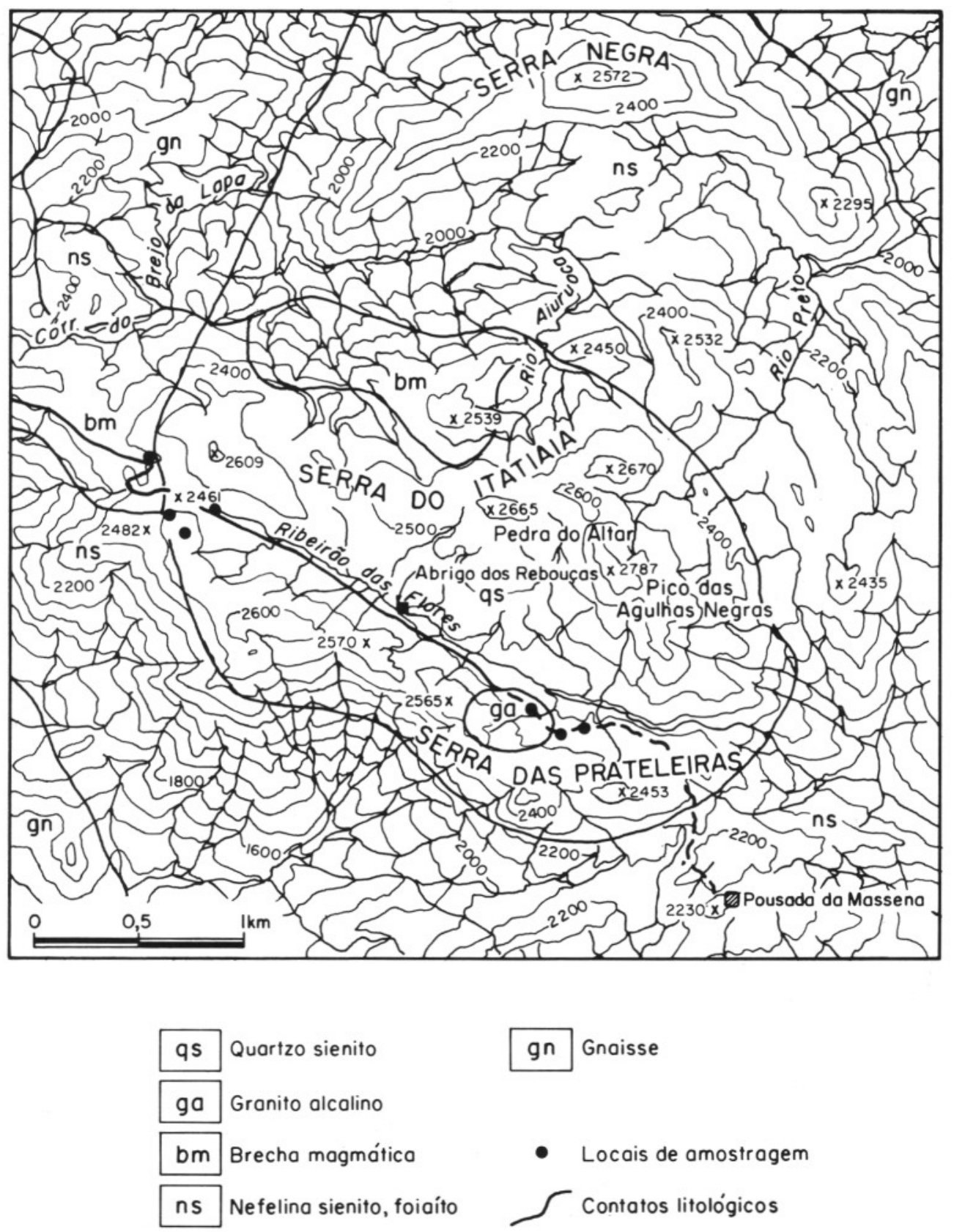

FIGURA 1 - Mapa topográfico-geológico da área do planalto do Itatiaia (baseado em RIBEIRO FILHO \& PENALVA, 1965) e localização dos pontos de amostragem.

tares de deferrificação, aquecimento e glicolagem foram executados em algumas destas amostras para identificação dos argilominerais. $\mathrm{O}$ estudo micromorfológico de 30 lâminas de colúvios e rocha alterada foi feito por microscopia óptica, utilizando-se a terminologia de BREWER (1974). Teores de matéria orgânica foram avaliados por gravimetria após oxidação e a porcentagem de carbono, determinada por via seca. Datação radiométrica de duas amostras de colúvio foi executada pela Beta Analytic Inc. (Miami EUA).

\section{OS DEPÓSITOS DE COLÚVIO}

Nas pequenas bacias alveolares, formadas ao longo do ribeirão das Flores e de seus afluentes, ocorrem dois níveis de rampas detríticas que se estendem da base de depósitos de tálus suspensos até as várzeas, com diminuição da declividade (de $14-16^{\circ}$ para $4-5^{\circ}$ ) e da granulometria dos materiais (figura 2). Estas duas gerações de colúvios foram interpretadas como leques aluviais, produto de retrabalhamentos sucessivos dos antigos tálus (MODENESI, 1989 e 1992). 


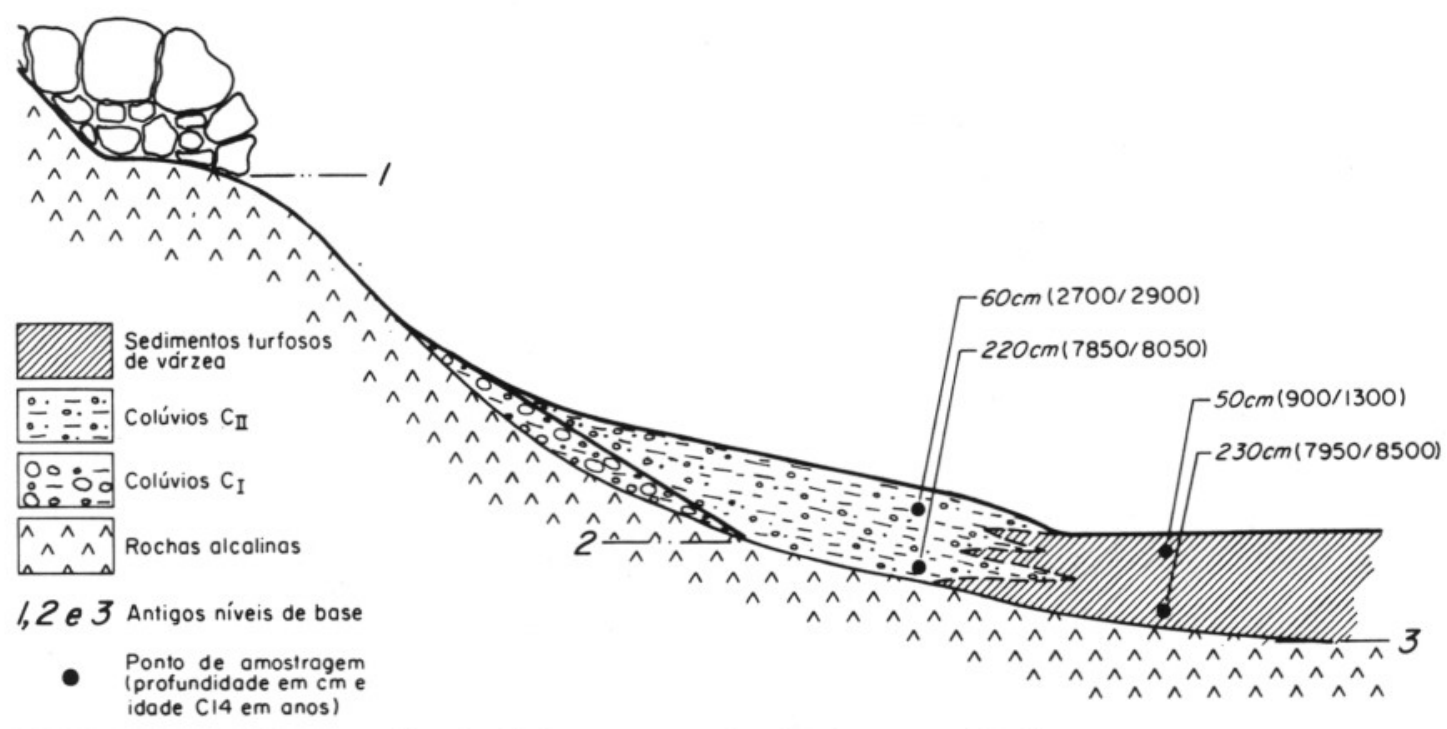

FIGURA 2 - Perfil esquemático das baixas vertentes do planalto e seus depósitos.

Colúvios $\mathrm{C}_{\mathrm{I}}$, mais antigos, repousam sobre a rocha alterada, têm espessura geralmente inferior a $1 \mathrm{~m}$, são maciços e compactos e desprovidos de estruturas, conglomeráticos e extremamente heterométricos, com blocos de rocha em diferentes graus de alteração. Sua matriz é argilosa, amarelada ou amarelo-brunada, com manchas esbranquiçadas e vermelho-amareladas devidas à presença de feldspato pertítico alterado e nódulos ferruginosos. Possui teores elevados de argila (48 a 50\%), conteúdos semelhantes em silte ( 22 a $25 \%$ ) e areia ( 25 a $30 \%$ ) e ainda grânulos (2 a 5\%), principalmente de feldspato em vias de alteração; grande quantidade de seixos (em média, $25 \%$ do total da amostra), blocos e matacões (com até $50 \mathrm{~cm}$ de eixo maior, freqüentemente com córtex de alteração) ocorrem dispersos em matriz mais fina. Corridas de lama ou terra teriam originado esta primeira geração dos colúvios, em climas úmidos e talvez menos frios, capazes de intemperizar os materiais de vertente e de fornecer a água necessária ao desencadeamento das corridas, provavelmente no Pleistoceno terminal, em seguida ao máximo glacial (MODENESI, 1992).

Os colúvios mais recentes $-\mathrm{C}_{\mathrm{II}}-$, com até $240 \mathrm{~cm}$ de espessura, formam o nível mais baixo de rampas e se estendem sobre os depósitos turfosos das várzeas. Menos heterométricos, diferenciam-se dos primeiros, principalmente, pela redução do número e tamanho dos clastos, angulares e subangulares, geralmente inferiores a 2 ou $3 \mathrm{~cm}$, excepcionalmente $5 \mathrm{~cm}$. De aspecto cascalhento, apresentam forte contraste de cor entre a matriz preta a bruno-acinzentada muito escura e os numerosos grânulos e pequenos seixos esbranquiçados (feldspato pouco alterado), amarelos (feldspato alterado) e avermelhados (nódulos ferruginosos). Sua matriz, como a dos $\mathrm{C}_{\mathrm{I}}$, é pouco ou fracamente selecionada, possui 32 a $60 \%$ de argila, 28 a $34 \%$ de silte e 19 a $49 \%$ de areia, distribuídos no perfil sem qualquer tendência nítida; a quantidade de seixos esparsos na matriz (até $8 \%$ do total da amostra) é inferior àquela verificada nos colúvios mais antigos. Os blocos e matacões contidos em $\mathrm{C}_{\mathrm{II}}$, ou a ele sobrepostos, ocorrem quase sempre menos alterados. $\mathrm{O}$ perfil tipo descrito na trilha da Pousada da Massena (figura 1) apresenta, sobre quartzo-sienito alterado in situ, $50 \mathrm{~cm}$ de colúvios heterométricos amarelados $-\mathrm{C}_{\mathrm{I}}-$ sotopostos a uma seqüência de $240 \mathrm{~cm}$ de materiais escuros e cascalhentos $-\mathrm{C}_{\mathrm{II}}-$ com variações de cor e textura e com níveis de concentração de grânulos e pequenos seixos de feldspato alterado, concreções ferruginosas e quartzo.

Essas descontinuidades, comuns nos perfis mais espessos, teriam sido originadas pela deposição de materiais ora mais finos ora mais cascalhentos, ou pela ação pós-deposicional do escoamento superficial sobre colúvios heterométricos; o enriquecimento em cascalho poderia refletir fases de intensificação da gelifração. As seqüências $\mathrm{C}_{\mathrm{II}}$ teriam sido depositadas por corridas de lama ou processos mais lentos de tipo solifluxão, capazes de mobilizar materiais intemperizados e depositá-los sem destruir completamente os perfis das formações superficiais ou solos subjacentes (MODENESI, 1992).

Datação radiométrica de amostras do perfil mais espesso de colúvios $\mathrm{C}_{\mathrm{II}}$ indicou idades de $7.950 \pm 100$ anos AP na parte basal do perfil 


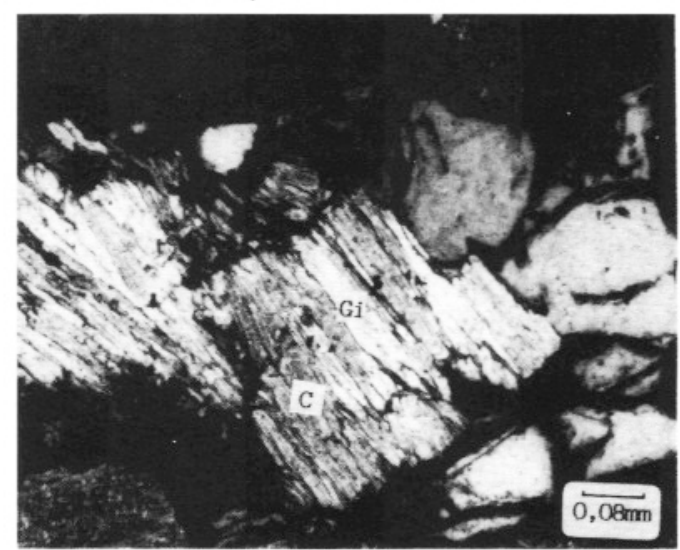

FOTO 1 - Isalterita (rocha alterada in situ, sob os colúvios, conservando a organização original da rocha). A pseudomorfose de biotita foi caulinizada (C) e algumas lamelas estão sofrendo gibbsitização (Gi), mostrando a tendência lateritizante do intemperismo na área. M.O., L.N.

(220 cm de profundidade, amostra VF.6.8., BETA 59286) e $2.790 \pm 80$ anos AP imediatamente abaixo dos horizontes ricos em raízes atuais $(60 \mathrm{~cm}$ de profundidade, amostra VF.6.3, BETA 59285). Essas idades e a datação dos sedimentos das várzeas - cerca de 8.200 na base e 1.090 no topo - confirmam a contemporaneidade e a interdigitação dos $\mathrm{C}_{\mathrm{II}}$ com os sedimentos de várzea (MODENESI, 1989 e 1992).

\section{CARACTERIZAÇÃO MINERALÓGICA E MICROMORFOLÓGICA DOS MATERIAIS}

Nos colúvios $\mathrm{C}_{\mathrm{I}}$ e $\mathrm{C}_{\mathrm{II}}$ os minerais primários mais abundantes são feldspato pertítico e quartzo, este último isolado ou em intercrescimento gráfico no feldspato potássico; além desses, aparecem, nos difratogramas e nas lâminas delgadas, micas (biotita e sericita) e, mais raramente, anfibólios e magnetita. Outros minerais acessórios citados na bibliografia sobre o maciço alcalino não foram detectados nos materiais analisados. Os principais minerais secundários são gibbsita, presente em todas as amostras, caulinita e argilominerais 2:1 (vermiculita e interestratificados biotita-vermiculita), este último em menor quantidade e essencialmente em $\mathrm{C}_{\mathrm{I}}$. Oxihidróxidos de ferro são raros, tendo sido detectados apenas em microscopia óptica.

Referência para as interpretações, a rocha alterada in situ, abaixo dos colúvios $\mathrm{C}_{\mathrm{I}}$ e $\mathrm{C}_{\mathrm{II}}$, constitui uma isalterita (rocha alterada conservando as texturas petrográficas e estruturas litológicas da rocha de origem) amarela (foto 1), com zonas localizadas e irregulares de material mais evoluído aloterítico (rocha alterada sem conservar aquelas texturas e estruturas originais). Os principais minerais primários - pertita e quartzo, que ocorrem em estado são ou parcialmente alterado, junto com os outros minerais (magnetita, biotita e sericita) - constituem o esqueleto (grãos de minerais primários, herdados da rocha de origem), que perfaz cerca de $30 \%$ do volume da isalterita. O plasma (conjunto dos minerais secundários, geralmente argilominerais e oxi-hidróxidos que, junto com o esqueleto e a porosidade, forma o fundo matricial) é normalmente primário, ou seja, conserva a organização original dos minerais primários que lhe deram origem, na forma de pseudomorfoses cauliníticogibbsíticas, mais ou menos perfeitas. O plasma secundário, presente nas zonas mais evoluídas, apresenta estrutura porfirosquélica (tipo de associação entre plasma e esqueleto, onde os grãos deste estão imersos num plasma quase contínuo); localizadamente apresenta accordéons cauliníticos bem desenvolvidos (foto 2). Plasmas primário e secundário șão formados por caulinita e gibbsita, com pequena presença de produtos ferruginosos. Argilominerais 2:1 ocorrem como produto da alteração das biotitas e anfibólios. $\mathrm{Na}$ alteração de feldspatos foi observada a presença de produtos isótropos, possivelmente compostos amorfos silicoaluminosos, como intermediários na sua caulinização ou gibbsitização.

Os colúvios $\mathrm{C}_{\mathrm{I}}$ e $\mathrm{C}_{\mathrm{II}}$ apresentam uma diferenciação vertical interna, relacionada à progressão do intemperismo e pedogênese atuais.

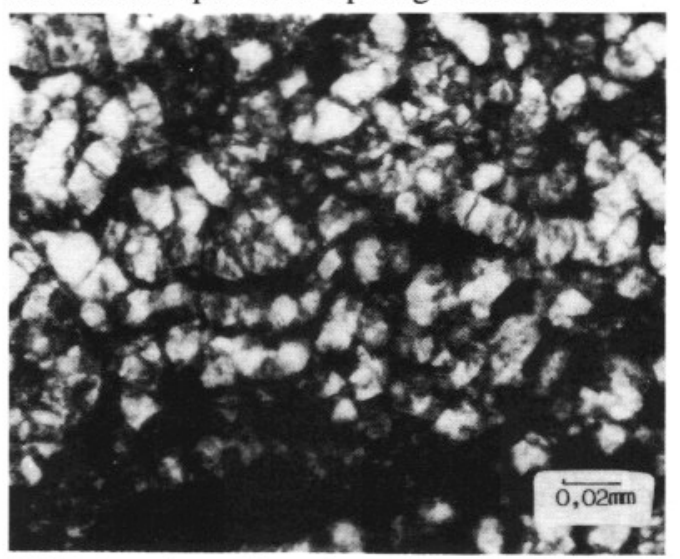

FOTO 2 - Accordéons de caulinita neoformada em zona de maior circulação dentro da isalterita, mostrando também a tendência geoquímica do intemperismo na área. M.O., L.P.

Colúvios $\mathrm{C}_{\mathrm{I}}$, de cor amarela, mostram, de baixo para cima, um aumento do volume ocupado pelo plasma secundário em relação ao volume do esqueleto, cujos grãos tornam-se, na mesma direção, fragmentados e alterados.

O plasma tem feições de remobilização que tanto podem indicar processos de intemperismo 
e pedoplasmação como de transporte. Esse plasma secundário é em geral porfirosquélico, podendo apresentar uma evolução com tendência à estrutura aglomeroplásmica (plasma constituindo material descontínuo, com fissuras separando aglomerados) nas suas partes superiores (foto 3). Pode apresentar feições nodulares e ferruginizações sobre alterorrelíquias. Ocorrem também lito e alterorrelíquias (respectivamente fragmentos da rocha original ou da isalterita correspondente, encontrados como relíquias dentro do plasma secundário), de dimensões milimétricas a centimétricas.

Colúvios $\mathrm{C}_{\mathrm{II}}$, de cor preta, apresentam, em seu conjunto, um esqueleto mais evoluído, com grãos menores e grau de alteração tão avançado quanto na parte superior dos $\mathrm{C}_{\mathrm{I}}$. Fragmentos de rocha são menos comuns em $\mathrm{C}_{\mathrm{II}}$, mas estão presentes. Em perfis desses colúvios, o esqueleto evolui ainda mais em direção ao topo, aumentando a quantidade relativa de plasma fino (argiliplasma) que envolve os grãos finos de quartzo e mica; nessa mesma direção, evidencia-se a estrutura aglomeroplásmica paralelamente ao aumento de porosidade (foto 4). Lito e alterorrelíquias são pouco freqüentes. $\mathrm{O}$ plasma desses colúvios pode ainda conter feições nodulares ou ferruginizações sobre alterorrelíquias.

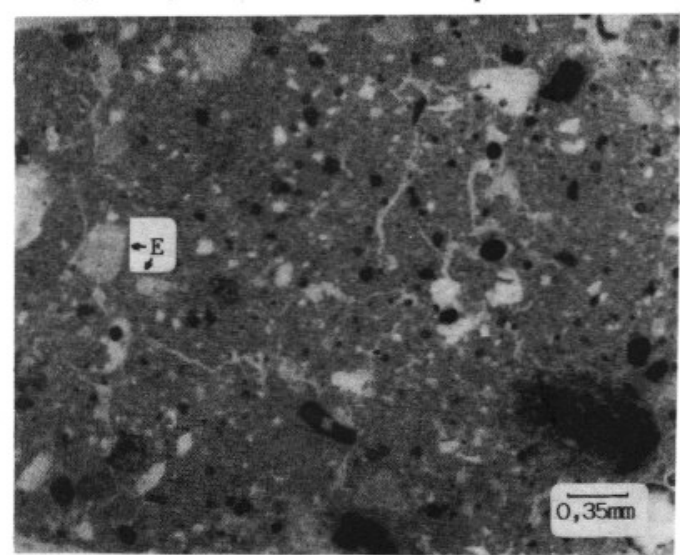

FOTO 3 - Fundo matricial da parte superior do colúvio $\mathrm{C}_{\mathrm{I}}$, mostrando estrutura porfirosquélica (grãos de esqueleto imersos num plasma maciço) já com tendência a evoluir para estrutura aglomeroplásmica. Os grãos de esqueleto (E) mostram formas e dimensões variadas e são, em geral, maiores que no colúvio $\mathrm{C}_{\mathrm{II}}$. M.O., L.N.

\section{CONSIDERAÇÕES FINAIS E CONCLUSÕES}

As filiações mineralógicas, convergindo para gibbsita e caulinita, indicam a tendência geral laterítica tanto nos materiais de colúvio $\left(\mathrm{C}_{\mathrm{I}}\right.$ e $\left.\mathrm{C}_{\mathrm{II}}\right)$ como nos perfis in situ, que mostram a alteração atual. Mesmo que o clima atual, característico da situação de cimeira montanhosa, compor- te temperaturas relativamente frias, o ritmo tropical das precipitações - com picos de chuva no verão - e os totais pluviométricos aliamse aos fatores locais de boa drenagem interna dos perfis e pobreza em silício das rochas iniciais na definição de um ambiente lateritizante. Rochas alcalinas em geral, como as encontradas no maciço de Itatiaia, são facilmente alteradas em materiais cauliníticos e gibbsíticos, devido à sua composição mineralógica (ausência ou pequena quantidade de quartzo e importância de feldspatos e feldspatóides, resultando numa relação $\mathrm{Al}_{2} \mathrm{O}_{3} / \mathrm{SiO}_{2}$ alta). A ocorrência de um estádio inicial na alteração dos feldspatos e nefelinas com formação de produtos amorfos silicoaluminosos refletiria uma alitização menos rápida. Argilominerais 2:1 encontrados nos materiais in situ e colúvios refletem tão-somente um primeiro estádio na evolução das micas, já chamado "estádio bissialítico transitório na laterização" (CHATELIN, 1972); esses argilominerais ocorrem em pseudomorfoses, muitas delas já apresentando caulinização e gibbsitização. Por outro lado, a ocorrência, nos dois colúvios, de grãos de esqueleto constituídos por quartzo com feições de dissolução corrobora a definição da tendência lateritizante.

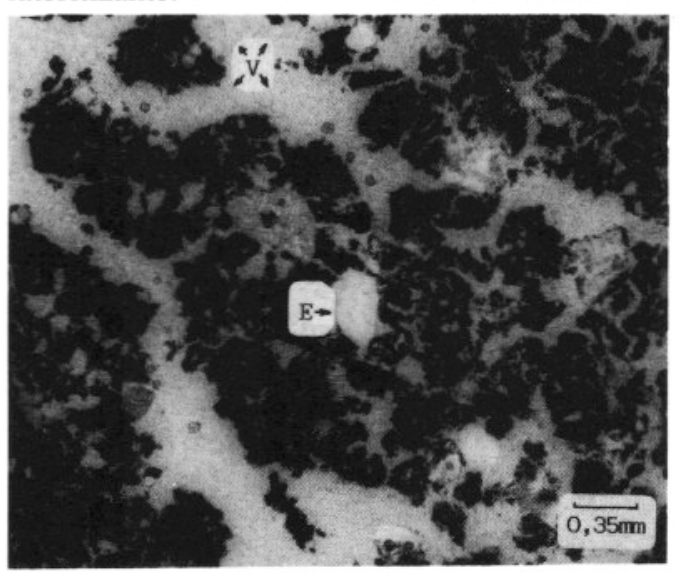

FOTO 4 - Fundo matricial da parte superior do colúvio $\mathrm{C}_{\mathrm{II}}$, mostrando alta porosidade. A estrutura aglomeroplásmica aqui registrada (onde o material apresenta alta porosidade e é bastante descontínuo) evidencia pedogênese avançada. V: porosidade; E: esqueleto. M.O., L.N.

O estudo micromorfológico mostra que, tanto em $\mathrm{C}_{\mathrm{I}}$ como em $\mathrm{C}_{\mathrm{II}}$, há mistura de materiais com diferentes graus de alteração (foto 5). Esta mistura é mais evidente nos colúvios $\mathrm{C}_{\mathrm{II}}$, caracterizados pela coexistência de plasma muito evoluído e esqueleto com alteração avançada, ao lado de fragmentos de rocha sã ou pouco alterada (embora pouco comuns) e esqueleto pouco alterado. $\mathrm{C}_{\mathrm{II}}$ apresenta, portanto, materiais com maiores contrastes de grau de alteração e pode conter simultaneamente, por exemplo, litorrelí- 
quias, plasma secundário aglomeroplásmico e esqueleto muito fragmentado. Estes contrastes, maiores que o comum num mesmo nível de alteração, indicariam mistura de materiais provenientes de níveis distintos, mas dentro da mesma tendência de lateritização (alitização + monossialitização).

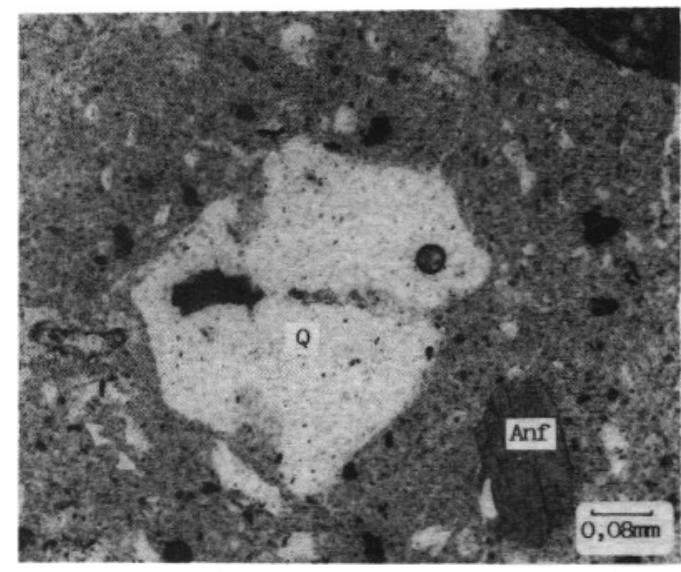

FOTO 5 - Material do colúvio $\mathrm{C}_{\mathrm{I}}$ mostrando a coexistência de grãos de esqueleto com grande contraste em graus de alteração: anfibólio inalterado (Anf) e quartzo bastante alterado (Q). Esta heterogeneidade de graus de alteração é causada pela mistura de materiais de diferentes níveis durante o transporte. M.O., L.N. (a) e L.P. (b).

Por outro lado, a diferenciação vertical interna observada nos dois colúvios, no que diz respeito (1) à evolução, em termos de dimensão e alteração dos grãos de esqueleto e das relíquias e (2) à estrutura do plasma (porfirosquélica ou aglomeroplásmica), evidencia a atuação de processos intempéricos e pedogenéticos pósdeposicionais (foto 6) naturalmente mais intensa nos $\mathrm{C}_{\mathrm{II}}$, sempre de mesma tendência.

Poder-se-ia concluir que os colúvios $\mathrm{C}_{\mathrm{I}} \mathrm{e}$ $\mathrm{C}_{\text {II }}$ proviriam de fontes sujeitas a uma mesma tendência de alteração, mas de materiais com diferentes graus de intemperismo e pedogênese. Em $C_{I}$, fragmentos milimétricos a centimétricos de rocha isoalterada ocorrem em meio a plasma evoluído. Já em $\mathrm{C}_{\mathrm{II}}$, altero e litorrelíquias bem menos comuns e grãos de esqueleto sempre menores parecem evidenciar proveniência de materiais inicialmente mais evoluídos.

O reconhecimento de apenas uma tendência de alteração em todas as formações superficiais das vertentes do planalto do Itatiaia sugere a permanência de condições ambientais semelhantes durante o período compreendido entre a alteração do regolito que originou $\mathrm{C}_{\mathrm{I}} \mathrm{e}$ a deposição da camada superficial de $\mathrm{C}_{\mathrm{II}}$. A tendência lateritizante observada na rocha alterada in situ e nos colúvios refletiria as condições de ligeiro aque- cimento e forte ampliação de umidade, que teriam persistido após o último máximo glacial.

Mesmo apresentando um grau de alteração semelhante para o conjunto dos materiais, os dois colúvios têm algumas diferenças macro e micromorfológicas que parecem reforçar as interpretações anteriores (MODENESI, 1992) sobre os processos atuantes na mobilização e deposição dos materiais de vertente.

A mistura de graus extremos de alteração encontrada nos colúvios mais recentes $\left(\mathrm{C}_{\mathrm{II}}\right)$, evidente apesar da ação pedogenética pós-deposicional, indica materiais originais desde o início mais evoluídos, confirmando assim o retrabalhamento da parte mais intemperizada de perfis situados a montante. Processos de coluviação com menor poder erosivo - provavelmente corridas de lama mais superficiais ou movimentos de massa lentos, de tipo solifluxão - teriam atingido apenas os horizontes superiores dos perfis incluindo, durante o transporte vertente abaixo, fragmentos de rocha menos alterada, provenientes dos afloramentos, matacões e blocos tão comuns nas encostas do planalto. Os níveis de concentração de pequenos seixos e grânulos que interrompem as seqüências $\mathrm{C}_{\mathrm{II}}$ corresponderiam a fases de gelifração mais intensa na fonte (MODENESI, 1992).

Constituídos por materiais intensamente argilificados mas pouco pedogeneizados, ricos em fragmentos das rochas subjacentes e com menores contrastes de alteração, os colúvios $C_{I}$ teriam sua origem em movimentos de massa que atingiram o regolito da área-fonte em maior profundidade, provavelmente corridas de lama provocadas pela saturação dos materiais intemperi-

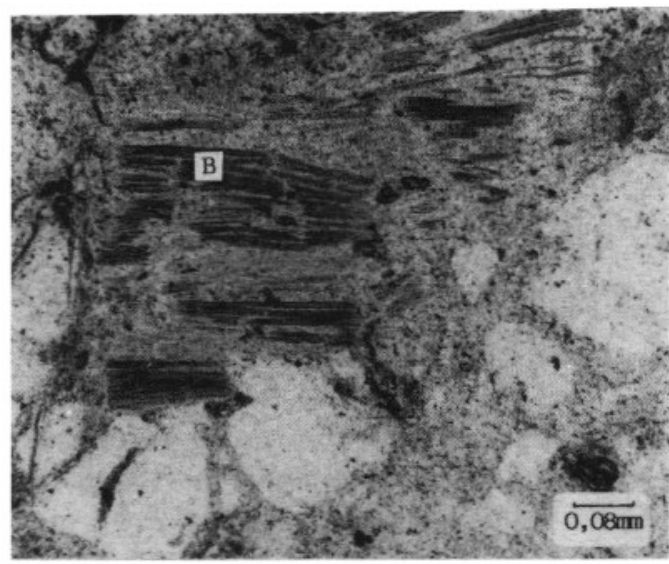

FOTO 6 - Lamelas de biotita alterada (B), mostrando fragmentação do grão e separação das partes, com invasão de plasma secundário. Estas feições evidenciam a ocorrência de alteração após a deposição do colúvio $\mathrm{C}_{\mathrm{I}}$. M.O., L.N.

zados situados a montante, in situ ou sobre os depósitos de tálus suspensos. Estes processos im- 
plicariam a existência de condições ambientais úmidas, com água suficiente para intemperizar os materiais de vertente e desencadear as corridas (MODENESI, 1988 e 1992).

Concluindo, os resultados da micromorfologia parecem confirmar mudança dos processos de coluviação nas vertentes, indicando possíveis variações nas condições ambientais do planalto do Itatiaia a partir do Pleistoceno terminal. Entretanto, estas variações não teriam sido suficientes para mudar o rumo da alteração, que reflete sempre a mesma tendência lateritizante. Das condições iniciais mais estáveis de climas úmidos e talvez mais quentes favoráveis à formação do regolito, ter-se-ia passado a uma fase de maior intensidade ou concentração das chuvas, capaz de explicar o alto conteúdo de água necessário ao desencadeamento das corridas. Nos últimos 8.000 anos, pequenas oscilações das condições ambientais, com predominância de umidade e variação das temperaturas acima ou abaixo das atuais, devem explicar as ocorrências de materiais ora finos, ora cascalhentos que caracterizam as seqüências coluviais mais recentes. As temperaturas relativamente elevadas do "optimum climaticum" (5 a 6 mil anos) que afetaram profundamente a geomorfologia costeira do Brasil Atlântico parecem não ter deixado registros significativos nos altos do Itatiaia. Os registros sedimentares recentes indicam flutuações ambientais de pequena amplitude e relativa continuidade. Importante para o esclarecimento das condições ambientais vigentes nas cimeiras do Itatiaia durante o Holoceno, esta hipótese poderá ser confirmada pelos resultados da palinologia dos sedimentos da várzea do Ribeirão das Flores, ora em conclusão.

\section{AGRADECIMENTOS}

A Aziz N. Ab'Saber e Adolpho J. Melfi pelas críticas e sugestões ao texto original. A Adilson Carvalho pela ajuda nos trabalhos de campo. Esta pesquisa foi realizada com auxílio da Fundação de Amparo à Pesquisa do Estado de São Paulo - FAPESP. As autoras são pesquisadoras do Conselho Nacional de Desenvolvimento Científico e Tecnológico - CNPq.

\section{REFERÊNCIAS BIBLIOGRÁFICAS}

ALMEIDA, F.F.M de. 1964. Fundamentos geológicos do relevo paulista. In "Geologia do Estado de São Paulo". Boletim, Inst. Geogr. e Geol., 41:167-263.

1976. The system of continental rifts bordering the Santos basin, Brazil. In: "Continental margins of Atlantic type". Anais Acad. Bras. Ciências. 48(suplem.): 15-26.

AMARAL, G.; BUSHE, J.; CORDANI, U.G.; KAWASHITA. K. \& REYNOLDS. J.H. 1967. Potassium-argon ages of alkaline rocks from Southern Brazil. Geoch. Cosmoch. Acta. 31:117-142.

AB'SABER, A.N. 1989. Introdução. In: "Campos de altitude". Gustavo Martinelli. Editora Index, p. 16-29. São Paulo.

BREWER, R. 1964. Fabric and mineral analysis of soils. J.Wiley and Sons, N.Y. Sidney, $470 \mathrm{p}$.

CHATELIN. Y. 1972. Les sols ferralitiques: historique, development et conaissance et formations de concepts actuels. INIT. DOC. TECHN., ORSTOM, Paris 20, 98 p.

DE MARTONNE. E. 1940. Problèmes morphologiques du Brésil Tropical Atlantique. Annales de Géographie 49(277): 1-27 e (278/9): 106-129.
FREITAS R.O. 1951. Ensaio sobre a tectônica moderna no Brasil. Boletim FFCL-USP (130). Geologia (6), 120p.

KING. L. 1956. A geomorfologia do Brasil Oriental. Rev. Bras. de Geografia 18(2):46-266.

LAMEGO, A. 1936. A análise tectônica e morfológica do sistema da Mantiqueira. In: "Congresso Panamericano de Engenharia de Minas e Geologia" 2․, Petrópolis. Anais 3:247-327.

MODENESI, M.C. 1980. Intemperismo e morfogênese no planalto de Campos do Jordão. São Paulo. Rev. Bras. de Geoc. $10(3): 213-225$.

1983. Weathering and morphogenesis in a tropical plateau. Catena 10(3):237-251.

1988. Significado dos depósitos correlativos quaternários em Campos do Jordão - São Paulo: implicações paleoclimáticas e paleoecológicas. Boletim Inst. Geol. (7), $155 \mathrm{p}$.

1989. Hillslopes forms and Quaternary deposits in the Itatiaia plateau $-\mathrm{RJ}-\mathrm{Bra}-$ zil. In: "International Symposium on global changes in South America during the Quaternary". Special Publication (1): 293-300. 
MODENESI, M.C. 1992. Depósitos de vertente e evolução quaternária do planalto do Itatiaia. Revista Inst. Geol. 13(1):31-46.

PENALVA, F. 1967. Geologia e tectônica da região do Itatiaia (sudeste do Brasil). Boletim FFCL-USP (302). Geologia (22): 95-106.
RIBEIRO Fo, E. 1967. Geologia e petrologia dos maciços alcalinos do Itatiaia e PassaQuatro. Boletim FFCL-USP (302). Geologia (22):5-93.

TEIXEIRA, D. 1961. Relevo e padrões de drenagem na chaminé vulcânica do Itatiaia. Boletim Paul. Geogr. (37): 3-12.

Endereço dos autores:

- May Christine Modenesi - Instituto Geológico - SMA - Caixa Postal 8772 - 04301-903 - São Paulo, SP - Brasil. - Maria Cristina Motta de Toledo - Instituto de Geociências. Universidade de São Paulo - Núcleo de Pesquisas em Geoquímica e Geofísica da Litosfera (Nupegel) - Caixa Postal 20.899 - 01498-301 - São Paulo, SP - Brasil. 